\title{
Simulação termodinâmica e sua aplicação na avaliação do desempenho de materiais refratários
}

\section{(Thermodynamic simulation and its application to evaluate the performance of refractory materials)}

\author{
A.P.Luz, V.C. Pandolfelli \\ Grupo de Engenharia de Microestrutura de Materiais - GEMM, Universidade Federal de S. Carlos - \\ Departamento de Engenharia de Materiais, Rod. Washington Luiz, km 235, C. P. 676, S. Carlos, SP, 13565-905 \\ ana_light@uol.com.br,vicpando@power.ufscar.br
}

\begin{abstract}
Resumo
A corrosão, oxidação e o desgaste de materiais refratários têm sido objeto de vários estudos ao longo dos últimos anos. Por se tratarem de fenômenos complexos que ocorrem em temperaturas elevadas e em condições extremas de uso, a aplicação de simulações termodinâmicas na avaliação do desempenho destes materiais tem ganho cada vez mais destaque. Com o objetivo de verificar quais os tipos de cálculos que podem ser elaborados e quais as vantagens e desvantagens deste tipo de análise, neste trabalho é proposto o uso do programa FactSage ${ }^{\circledR}$ no estudo do desempenho de diversos refratários. O propósito deste trabalho vai além de uma simples revisão dos cálculos já efetuados na literatura, uma vez que várias outras simulações termodinâmicas foram elaboradas e discutidas. Os resultados destas avaliações comprovam que as informações provenientes destas análises podem auxiliar no entendimento das etapas e reações envolvidas na corrosão e desgaste dos refratários. No entanto, nenhum indicativo dos aspectos cinéticos e da distribuição espacial de cada produto de reação formado é fornecido nestes cálculos. Assim, para o completo entendimento dos mecanismos de reação são necessárias ambas as análises, termodinâmica e microestrutural.
\end{abstract}

Palavras-chave: análise termodinâmica, FactSage, corrosão, oxidação.

\begin{abstract}
Corrosion, oxidation and wear of the refractory materials have been studied during the latest years. These phenomena are complex and usually are carried out at high temperatures and severe working conditions. Thus, the use of thermodynamic simulations to evaluate the refractories performance has been receiving a particular attention lately. In order to verify which calculations can be developed and the advantages and disadvantages of these analyses, the use of Factsage ${ }^{\circledR}$ software to study the performance of several refractories is proposed in this work. The aim of this paper goes beyond of a simple review of the calculations presented in the literature, because several thermodynamic simulations were carried out and discussed herein. The collected results proved that these analyses can be helpful to understand the several steps and reactions involved in corrosion and wear phenomenon of refractory materials. However, any information about the kinetics aspects and distribution of the reaction products are not provided in these calculations. Therefore, aiming to better understand the reactions mechanisms of some transformations, both analyses, thermodynamic and microstructural, are required.
\end{abstract}

Keywords: thermodynamic analyses, FactSage, corrosion, oxidation.

\section{INTRODUÇÃO}

Dados e cálculos termodinâmicos são importantes para entender o fenômeno de corrosão e oxidação de refratários. Estes cálculos são baseados na minimização da energia livre do sistema, sendo possível deduzir a natureza das fases sólidas, líquidas e gasosas, assim como, sua composição química e reação na condição de equilíbrio [1,2].

A corrosão de materiais refratários ocorre normalmente a elevadas temperaturas e sob condições extremas de uso, as quais são dificilmente reproduzidas em escala laboratorial. A forma mais eficiente de se avaliar o fenômeno de corrosão envolve: cálculos termodinâmicos; fatores cinéticos; ensaios práticos realizados em laboratório e comparados com dados coletados em testes realizados em escala industrial.

Devido a complexidade das composições refratárias, deve-se levar em consideração também as características particulares de cada material, como a porosidade e o papel desempenhado pelos multicomponentes dos refratários (agregados e matriz). Além disso, também se faz necessário avaliar a influência de alguns parâmetros, tais como: viscosidade da fase líquida, tensões superficiais nas diferentes interfaces e molhabilidade de escórias e metais fundidos $[2,3]$. Tendo disponível todas estas informações o processo de corrosão pode ser entendido de uma forma mais ampla e clara. 
Neste trabalho será explorado o uso de uma ferramenta termodinâmica - programa FactSage ${ }^{\circledR}$ - na avaliação da corrosão e oxidação de refratários. A partir das informações fornecidas em diversos trabalhos encontrados na literatura, novos cálculos foram elaborados, reproduzidos e discutidos. Assim, foi possível verificar quais os tipos de simulações podem ser elaboradas e quais as vantagens e desvantagens deste tipo de avaliação.

\section{Mecanismos de corrosão}

Como as ferramentas termodinâmicas são amplamente aplicadas nas avaliações do fenômeno de corrosão de refratários, nesta seção serão apresentados alguns dos principais mecanismos e tipos de reações que podem ocasionar o desgaste e comprometer o desempenho destes materiais. Na literatura, diversas publicações abordam mecanismos, reações e exemplos práticos da corrosão de refratários destinados ao processo siderúrgico [2-9]. Algumas das possíveis reações são mostradas esquematicamente na Fig. 1.

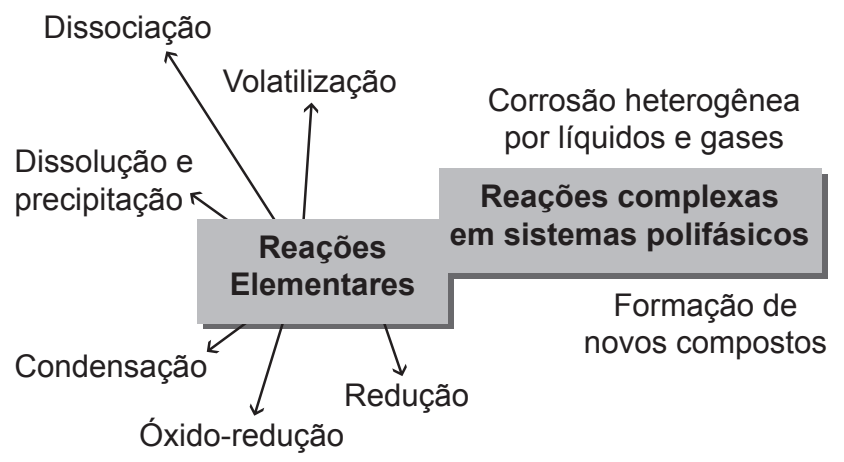

Figura 1: Tipos de reações que contribuem para a corrosão de refratários [4].

[Figure 1: Reactions that induce corrosion [4].]

Quando uma das fases consideradas na corrosão é um líquido, a reação será freqüentemente controlada pela direta dissolução do refratário com ou sem precipitação de outros componentes, por reações de óxido-redução ou por reações complexas envolvendo a formação de novas fases. A corrosão por gases está relacionada a reações de redução, óxido-redução ou a combinação de dissociação, volatilização e condensação [4].

\section{Dissolução dos refratários}

O gradiente do potencial químico (diferenças entre as composições química do sólido e líquido) é o responsável pelo avanço deste tipo de corrosão. Fases de natureza química distintas tendem a reagir mais facilmente em alta temperatura e assim, em geral, uma forma de limitar a extensão da dissolução consiste em colocar em contato refratários e líquidos com naturezas similares. Por exemplo, refratários de $\mathrm{MgO}$ e $\mathrm{CaO}$ são básicos e tem um bom desempenho quando em contato com escórias básicas.
Os principais fatores que constituem os mecanismos de dissolução são: reação química na interface sólido-líquido ou transporte (ou difusão) das espécies [3, 4].

A taxa da dissolução direta do sólido no líquido pode ser representada pela equação de Nernst [3]:

$$
\mathrm{J}=\mathrm{D}\left(\mathrm{C}_{\mathrm{s}}-\mathrm{C}_{\mathrm{m}}\right) / \delta
$$

na qual D é o coeficiente de difusão $\left(\mathrm{m}^{2} \mathrm{~s}^{-1}\right), \mathrm{C}_{\mathrm{m}}$ e $\mathrm{C}_{\mathrm{s}}$ são, respectivamente, concentração e solubilidade de saturação do refratário no líquido $\left(\mathrm{g} . \mathrm{m}^{-3}\right)$, e $\delta$ é a espessura efetiva da camada intermediária na interface entre sólido-líquido (m).

A possível dissolução de alguns óxidos presentes nos refratários pode ser avaliada pela solubilidade de saturação máxima destas fases na escória líquida. Felizmente, estes dados podem ser determinados por meio de cálculos termodinâmicos ou diagramas de equilíbrio. Verificando a diferença entre as concentrações e as solubilidades de saturação dos principais componentes do refratário na escória, sua resistência relativa ao ataque pelo líquido pode ser estimada, e assim, a influência das composições dos refratários na resistência a corrosão pode ser prevista [10]. Por exemplo, a Fig. 2 mostra a evolução da solubilidade de saturação do $\mathrm{Al}_{2} \mathrm{O}_{3}$, obtido a partir da análise de diagramas quaternários de $\mathrm{Al}_{2} \mathrm{O}_{3}-\mathrm{CaO}-\mathrm{SiO}_{2}-\mathrm{xMgO}$. De acordo com o valor da basicidade da escória $\left(\mathrm{CaO} / \mathrm{SiO}_{2}\right)$, é possível, por meio destes dados, estimar a extensão da dissolução da alumina no líquido.

A dissolução de um sólido também pode resultar na precipitação de novas fases. Nesta situação a taxa de remoção dos produtos de reação pela difusão é mais lenta do que a taxa da reação química, resultando na formação de uma camada desta nova fase na interface sólido-líquido [3]. Este processo pode resultar em um efeito positivo, pois as fases formadas tendem a atuar como uma barreira, evitando a penetração do líquido e a continuidade da corrosão. As possíveis fases que

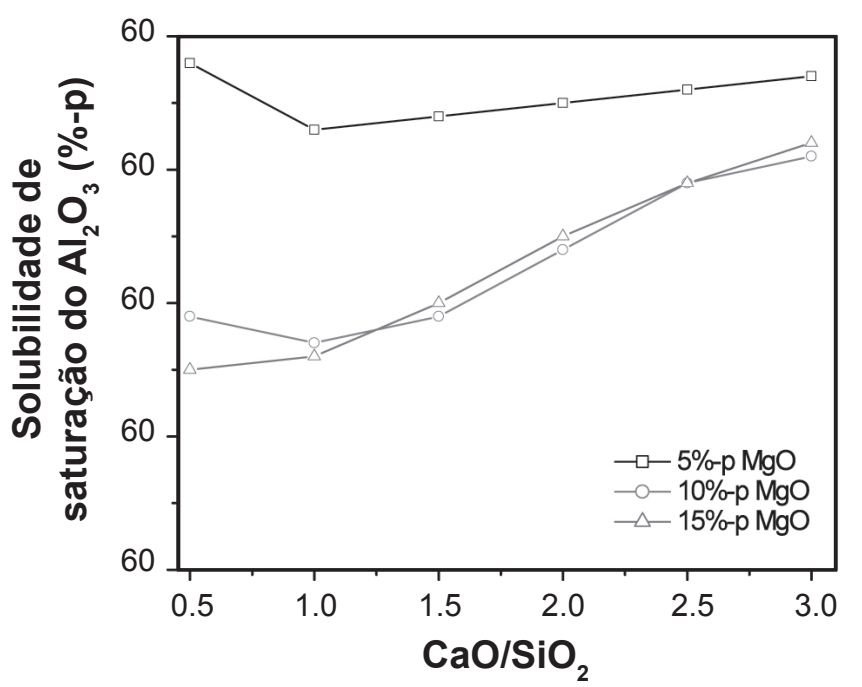

Figura 2: Efeito da basicidade na solubilidade de saturação de $\mathrm{Al}_{2} \mathrm{O}_{3}$ em escórias contendo $\mathrm{Al}_{2} \mathrm{O}_{3}-\mathrm{CaO}-\mathrm{SiO}_{2}-\mathrm{xMgO}$ a $1600{ }^{\circ} \mathrm{C}$.

[Figure 2: Basicity effect on the saturation solubility of $\mathrm{Al}_{2} \mathrm{O}_{3}$ in $\mathrm{Al}_{2} \mathrm{O}_{3}-\mathrm{CaO}-\mathrm{SiO}_{2}-\mathrm{xMgO}$ slags at $1600^{\circ} \mathrm{C}$.] 


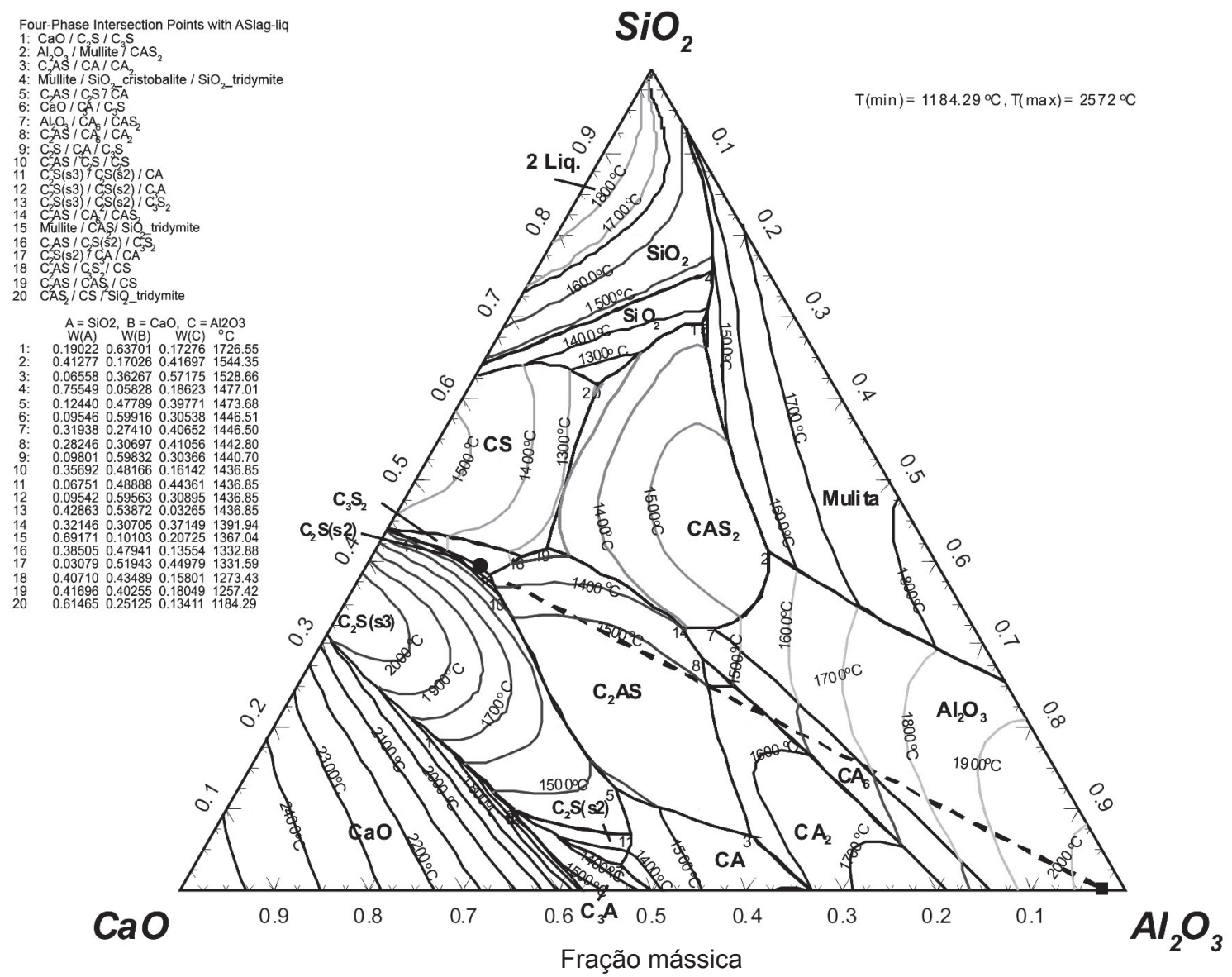

Figura 3: Projeção liquidus do sistema $\mathrm{Al}_{2} \mathrm{O}_{3}-\mathrm{CaO}-\mathrm{SiO}_{2}$ obtida pelo programa FactSage ( $\square$ composição do refratário e $\bullet$ composição da escória). [Figure 3: Liquidus projection of $\mathrm{Al}_{2} \mathrm{O}_{3}-\mathrm{CaO}-\mathrm{SiO}$, attained by FactSage software ( $\mathbf{\square}$ refractory and $\bullet$ slag compositions).]

podem ser precipitadas também podem ser estimadas a partir dos diagramas de fases do sistema em estudo ou por meio de cálculos termodinâmicos. Por exemplo, considerando o sistema $\mathrm{CaO}-\mathrm{Al}_{2} \mathrm{O}_{3}-\mathrm{SiO}_{2}$, é possível determinar quais fases podem ser formadas durante a corrosão de refratários com alto teor de $\mathrm{Al}_{2} \mathrm{O}_{3}$ quando em contato com escórias fundidas (Fig. 3). As fases que poderão ser formadas no contato entre um refratário 98\%-p $\mathrm{Al}_{2} \mathrm{O}_{3}$ - 2\%-p CaO e uma escória 13\%-p

Tabela I - Temperaturas liquidus e solidus de alguns materiais (dados obtidos através de cálculos termodinâmicos).

[Table I - Liquidus and solidus temperatures of some materials (all values were attained by thermodynamic calculations).]

\begin{tabular}{cccc}
\hline Sistema & $\begin{array}{c}\text { Composição } \\
(\%-p)\end{array}$ & $\begin{array}{c}\mathrm{T}_{\text {liquidus }} \\
\left({ }^{\circ} \mathrm{C}\right)\end{array}$ & $\begin{array}{c}\mathrm{T}_{\text {solidus }} \\
\left({ }^{\circ} \mathrm{C}\right)\end{array}$ \\
\hline $\begin{array}{c}\mathrm{Al}_{2} \mathrm{O}_{3}-\mathrm{CaO} \\
(\text { refratário })\end{array}$ & $98-2$ & 2038 & 1833 \\
$\begin{array}{c}\mathrm{Al}_{2} \mathrm{O}_{3}-\mathrm{CaO}-\mathrm{SiO}_{2} \\
\text { (escória) }\end{array}$ & $13-48,1-38,9$ & 1376 & 1273 \\
$\begin{array}{c}50 \% \text { refratário + } \\
50 \% \text { escória }\end{array}$ & $55,5-25-19$ & 1593 & 1392 \\
\hline
\end{tabular}

$\mathrm{Al}_{2} \mathrm{O}_{3}-48,1 \%$-p $\mathrm{CaO}-38,9 \%$-p $\mathrm{SiO}_{2}$ são: $\mathrm{Al}_{2} \mathrm{O}_{3}-\mathrm{CA}_{6}-$ $\mathrm{CA}_{2}-\mathrm{C}_{2} \mathrm{AS}-\mathrm{C}_{2} \mathrm{~S}$ (sendo $\mathrm{C}=\mathrm{CaO}, \mathrm{A}^{2}=\mathrm{Al}_{2} \mathrm{O}_{3}$ e $\mathrm{S}=\mathrm{SiO}_{2}$ ), conforme os campos interceptados pela linha tracejada indicada na Fig. 3.

Além disso, outras informações podem também auxiliar na avaliação da dissolução dos refratários quando em contato com líquidos. Alguns cálculos termodinâmicos permitem determinar com precisão qual a temperatura liquidus (temperatura a partir da qual todo o material se encontra no estado líquido) e solidus (acima desta temperatura há a presença de fase líquida, porém parte do material ainda está no estado sólido) de qualquer composição desejada. Assim é possível determinar as temperaturas referentes ao líquido formado a partir do refratário sólido, da escória ou no contato entre estes materiais (veja exemplo, Tabela I). Tais informações são importantes para a seleção dos materiais refratários.

\section{Dissociação e volatilização}

As reações desta natureza ocorrem devido a influência da atmosfera e particularmente da pressão de oxigênio ou vácuo no ambiente o qual o refratário é exposto. Refratários de magnésia-cromo, empregados em fornos destinados ao tratamento e degasificação de aços, são os materiais que 
mais estão propensos a sofrerem desgaste devido a reações de dissociação e volatilização de seus componentes. A volatilização do óxido de cromo é bastante complexa e pode apresentar as seguintes características [4]: poderá haver a dissociação do óxido de cromo com a formação de várias outras espécies; a reação dependerá fortemente da natureza dos gases presentes no ambiente; a pressão parcial de oxigênio tem um papel importante, pois a volatilidade deste óxido aumentará com o aumento de $\mathrm{pO}_{2}$.

Atualmente, as operações de degasificação a vácuo de aços tem recebido grande atenção [11-13]. A aplicação combinada de cálculos termodinâmicos de equilíbrio e o modelamento computacional do comportamento de fluxo do líquido têm permitido obter melhores previsões sobre o desgaste dos materiais refratários contendo óxido de cromo [13].

\section{Óxido-redução e carbo-redução}

Em elevadas temperaturas existe um grande número de reações de redução e carbo-redução que podem ocorrer em virtude da presença de: fases secundárias presentes no refratário, fontes de carbono (grafite, carbono amorfo, etc.) e elementos metálicos [4]. A adição de carbono em refratário tem sido fonte de vários estudos [14-17]. A sua presença contribui para o aumento da condutividade térmica, da energia de fratura, da resistência ao dano por choque térmico e aumento da resistência ao ataque por escória dos refratários. O carbono tem como função principal aumentar a vida útil dos refratários, devido a sua inferior molhabilidade por óxidos fundidos e ao desenvolvimento de novos mecanismos envolvendo a carbo-redução em altas temperaturas [4, 14]. Entretanto, a principal desvantagem da incorporação de carbono é a sua alta susceptibilidade à oxidação em elevadas temperaturas. Uma forma efetiva de prevenir a oxidação dos refratários contendo carbono envolve o uso de substâncias conhecidas como antioxidantes (materiais metálicos e não metálicos), os quais reagem preferencialmente com o oxigênio ou com o próprio carbono diminuindo sua taxa de oxidação [16, 18]. Vários exemplos destas reações são encontrados na literatura, principalmente devido ao uso cada vez mais acentuado de antioxidantes [18]. Cálculos termodinâmicos não são usados somente para prever o comportamento de reação dos antioxidantes a elevadas temperaturas, mas também podem ajudar na seleção de aditivos mais apropriados para melhorar o desempenho de refratários contendo carbono [15, 17, 19].

\section{SIMULAÇÕES TERMODINÂMICAS}

Alguns trabalhos científicos exploram o uso de ferramentas como os programas FactSage, $\mathrm{F}^{*} \mathrm{~A} * \mathrm{C}^{*} \mathrm{~T}-$ (Facility for the Analysis of Chemical Thermodynamics) ou ChemSage para avaliar e prever o comportamento dos materiais refratários quando expostos a severas condições de uso [1, 4, 16, 17, 20-22]. FactSage é um programa desenvolvido em conjunto pelos grupos CRCT - (Center for Research in Computacional Thermochemistry - Montreal) and GTT-Technologies (Aachen) e é o resultado da fusão entre os programas FACT-Win/F*A*C*T e ChemSage/ SOLGAMIX. Ele é composto por uma série de módulos de informações, bancos de dados, cálculos e simulações que possibilitam o acesso e a combinação de substâncias puras e soluções. Esta é uma ferramenta poderosa, a qual permite a realização de uma ampla faixa de cálculos termoquímicos destinados as áreas de: metalurgia, materiais, engenharia química, química inorgânica, geoquímica, eletroquímica, etc. Adicionalmente, este programa fornece informações sobre as fases formadas, suas proporções e composições, as atividades individuais de cada componente químico e as propriedades termodinâmicas para várias composições, pressões e temperaturas [23]. De acordo com os criadores do programa, atualmente o FactSage é utilizado em mais de 250 universidades e 250 empresas ao redor do mundo, como uma ferramenta para a pesquisa e ajuda educacional. Existe também a perspectiva de que ele se torne cada vez mais usado tanto nas áreas acadêmica e industrial.

\section{Exemplos de simulações termodinâmicas encontradas na literatura}

Nesta seção são apresentados resultados obtidos com o uso do programa FactSage. A seguir, alguns diagramas e cálculos foram elaborados, reproduzidos e reavaliados com base em informações contidas em alguns trabalhos encontrados na literatura.

Corrosão de refratários quando em contato com escórias líquidas

Alguns autores propõe uma metodologia para a avaliação do comportamento de corrosão de refratários de $\mathrm{Al}_{2} \mathrm{O}_{3}-\mathrm{MgO}$ com o uso de cálculos termodinâmicos [1]. Este tipo de simulação consiste na avaliação da mistura proporcional entre o refratário e um líquido, possibilitando a avaliação da reação dos materiais em todas as possíveis proporções, em função da taxa de reação $(<\mathrm{A}>$ ) na temperatura e pressão desejadas. A taxa ou avanço da reação, por sua vez, é definida pela razão:

$$
<\mathrm{A}>=(\mathrm{R}) /[(\mathrm{S})+(\mathrm{R})]
$$

sendo $(\mathrm{S})+(\mathrm{R})=1$ ( $\mathrm{R}$ corresponde ao refratário e $\mathrm{S}$ a escória ou líquido estudado).

Todos os outros parâmetros (temperatura, pressão) são considerados constantes nesta avaliação. O objetivo deste método é verificar as possíveis transformações no contato inicial entre o refratário e o líquido. Neste caso, a modificação da composição do líquido e sua saturação não são consideradas (a cada reação sempre são utilizados as composições originais do refratário e do líquido). A Fig. 4 ilustra a forma como são conduzidos estes cálculos.

Os autores do trabalho citado [1] afirmam que, para usar uma ferramenta termodinâmica de forma confiável é necessário validar o banco de dados utilizado por meio 


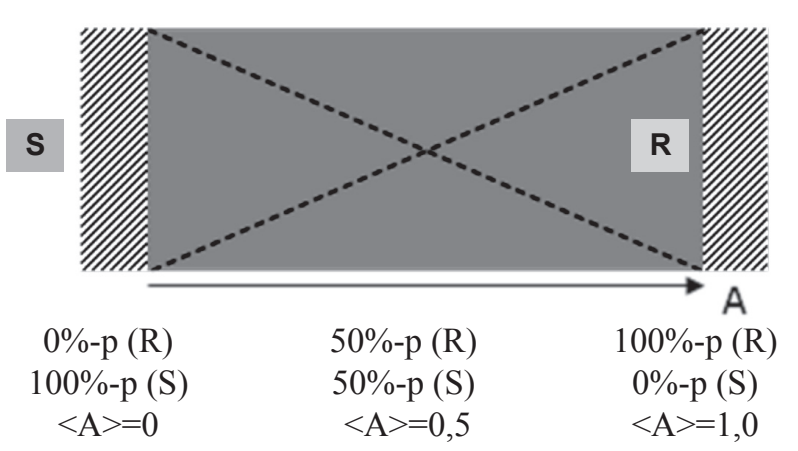

Figura 4: Mistura proporcional entre escória (S) e refratário (R) [1]. [Figure 4: Proportional mixture between slag (S) and refractory (R) [1].]

de cálculos e simulações em sistemas mais simples. Para comprovar isto, também foram elaborados aqui alguns diagramas binários e estes, em seguida, foram comparados com dados encontrados na literatura (Fig. 5 [24], 6 [25]). Em virtude dos bons resultados obtidos nestas simulações, o próximo passo consistiu na avaliação das possíveis reações envolvendo a mistura proporcional entre escórias e refratários. Além disso, cálculos determinando as temperaturas liquidus e solidus do refratário e das escórias também foram realizados. Algumas inconsistências foram observadas entre os dados obtidos pelos presentes autores e os apresentados no trabalho de Berjonneau et al [1]. Por exemplo, é destacado que na seção 4.2.1 do trabalho citado [1] que a $\mathrm{T}_{\text {liquidus }}$ da escória com 64,5\% moles de $\mathrm{Al}_{2} \mathrm{O}_{3}$ e $35,5 \%$ moles $\mathrm{CaO}$ é $1365{ }^{\circ} \mathrm{C}$. No entanto, de acordo com o diagrama binário $\mathrm{Al}_{2} \mathrm{O}_{3}-\mathrm{CaO}$ (Fig. 7), a temperatura liquidus desta mesma escória é igual a $1761{ }^{\circ} \mathrm{C}$. Adicionalmente, cálculos do trabalho atual elaborados no módulo EQUILIB do programa FactSage também confirmaram esta temperatura. Foram também verificadas algumas diferenças nos resultados envolvendo a avaliação das possíveis fases formadas a partir da mistura entre escória-refratário. Mesmo quando foram utilizados os mesmos bancos de dados e parâmetros de cálculos, os resultados que os presentes autores obtiveram foram distintos, principalmente nos valores dos teores das fases formadas na interface dos materiais avaliados. Foram verificadas ainda algumas discrepâncias entre os resultados das simulações usando o método da mistura proporcional apresentado no trabalho citado [1] e os diagramas de equilíbrio do sistema $\mathrm{Al}_{2} \mathrm{O}_{3}-\mathrm{CaO}-\mathrm{MgO}$ e $\mathrm{Al}_{2} \mathrm{O}_{3}-\mathrm{CaO}-\mathrm{SiO}_{2}-\mathrm{MgO}$ [26]. Apesar das diferenças que foram verificadas nos resultados calculados, o trabalho em questão destaca um ponto importante - deve-se efetuar a análise do contato de escórias líquidas com agregados ou com a matriz do refratário isoladamente. Concretos refratários são materiais que possuem microestrutura complexa, sendo constituídos por partículas finas (matriz) e agregados refratários, além de conter aditivos e agentes ligantes. A maior porosidade e menor textura da matriz a torna mais reativa do que os agregados. Os grãos maiores, por sua vez, somente são atacados superficialmente, podendo haver o aparecimento de novas fases nesta região [27]. Com base nas informações dos artigos pesquisados $[1,4,16,17,27]$, acredita-se que devido a complexidade das composições dos materiais refratários, o estudo individual do contato entre agregados-escória e matriz-escória seja o mais aconselhável para entender os mecanismos de corrosão envolvidos. Por exemplo, a mistura proporcional ou contato entre agregados de $\mathrm{Al}_{2} \mathrm{O}_{3}$ com uma escória contendo 50\%-p de $\mathrm{CaO}, 30 \%$-p $\mathrm{Al}_{2} \mathrm{O}_{3}$ e 20\%-p de $\mathrm{SiO}_{2}$ foi avaliado no presente trabalho com o programa FactSage, na temperatura de $1600{ }^{\circ} \mathrm{C}$. De acordo com a Fig. 8, a $1600{ }^{\circ} \mathrm{C}$ haverá inicialmente a reação entre alumina e o $\mathrm{CaO}$ da escória líquida, levando a formação da fase $\mathrm{CA}_{6}\left(\mathrm{CaAl}_{12} \mathrm{O}_{19}\right)$ na interface sólido-líquido $(0,77<\mathrm{A}$ $<1)$. Esta reação continuará a ocorrer enquanto houver o contato entre a escória e a alumina. Após a formação de uma camada superficial de $\mathrm{CA}_{6}$ sobre a alumina, esta nova fase atuará como uma barreira, diminuindo a penetração do líquido na estrutura do material sólido [1]. No intervalo
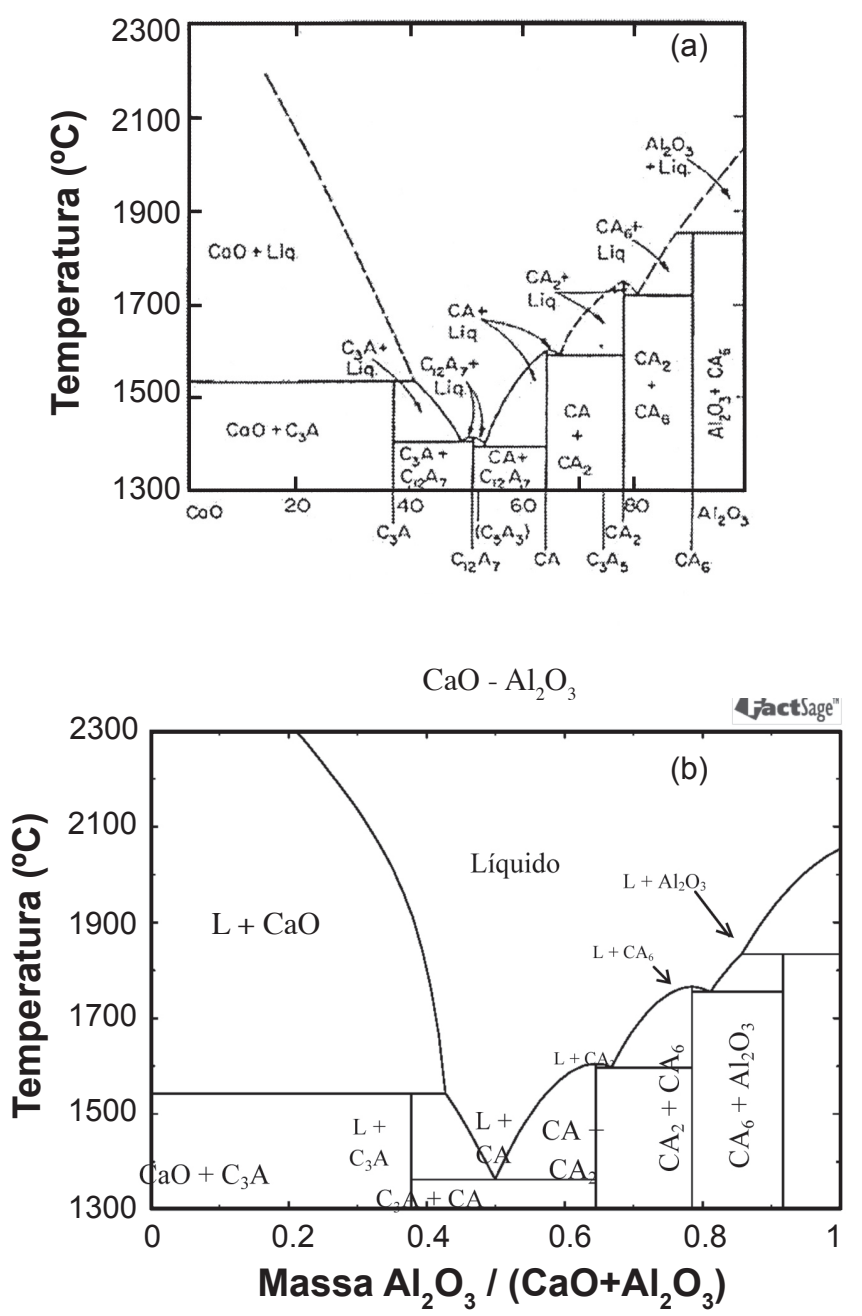

Figura 5: Diagrama de fases $\mathrm{Al}_{2} \mathrm{O}_{3}-\mathrm{CaO}$ : (a) obtido na literatura [24] e (b) a partir de cálculos do programa FactSage realizados neste trabalho.

[Figure 5: $\mathrm{Al}_{2} \mathrm{O}_{3}$-CaO phase diagrams: (a) from literature [24] and (b) attained with the FactSage calculation in this work.] 

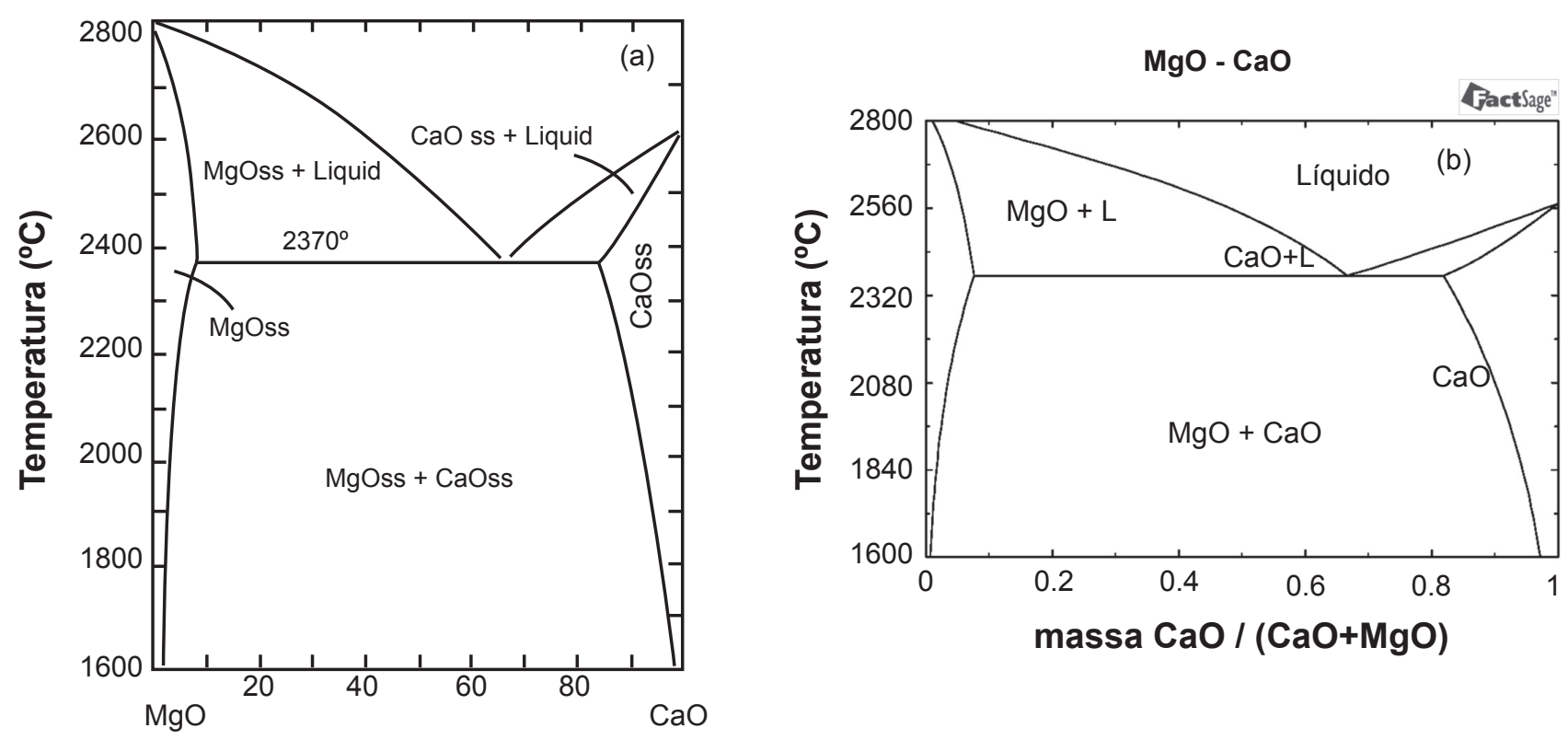

Figura 6: Comparação entre os diagramas $\mathrm{MgO}-\mathrm{CaO}$ obtidos: (a) na literatura [25] e (b) a partir das simulações efetuadas neste trabalho.

[Figure 6: Comparison between $\mathrm{MgO}-\mathrm{CaO}$ phase diagrams attained: (a) from literature [25] and (b) from the simulations carried out in this work.]

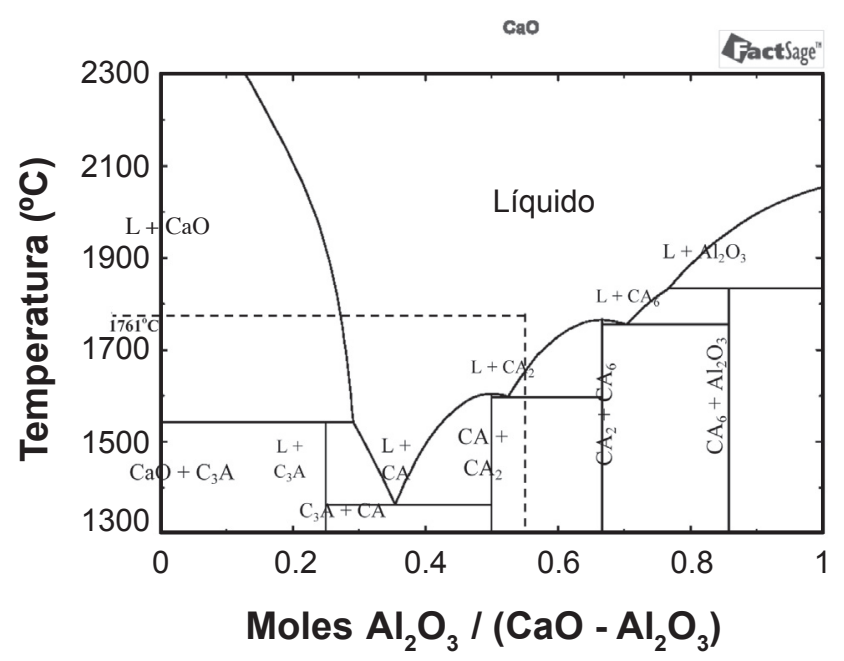

Figura 7: Diagrama $\mathrm{Al}_{2} \mathrm{O}_{3}-\mathrm{CaO}$ (fração molar) obtido no programa FactSage. As linhas tracejadas indicam a composição e temperatura liquidus da escória avaliada por Berjonneau et al [1].

[Figure 7: $\mathrm{Al}_{2} \mathrm{O}_{3}-\mathrm{CaO}$ phase diagram (molar fraction) attained with Factsage software. The dashed lines indicate the composition and liquidus temperature of the slag evaluated by Berjonneau et al. [1].]

entre $0,72<\mathrm{A}<0,77$ (Fig. 8), $\mathrm{CA}_{6}$ se tornará a única fase em contato com o líquido, indicando que esta fase sólida atuará na inibição o contato entre a escória e a alumina. Posteriormente, devido as variações na composição da escória (p.e., consumo de $\mathrm{CaO}$ para gerar a formação de $\mathrm{CA}_{6}$ e aumento de $\mathrm{Al}_{2} \mathrm{O}_{3}$ proveniente da dissolução do refratário), a fase $\mathrm{CA}_{2}\left(\mathrm{CaAl}_{4} \mathrm{O}_{7}\right)$ irá ser formada decorrente da interação entre líquido e $\mathrm{CA}_{6}$ entre $0,52<\mathrm{A}$

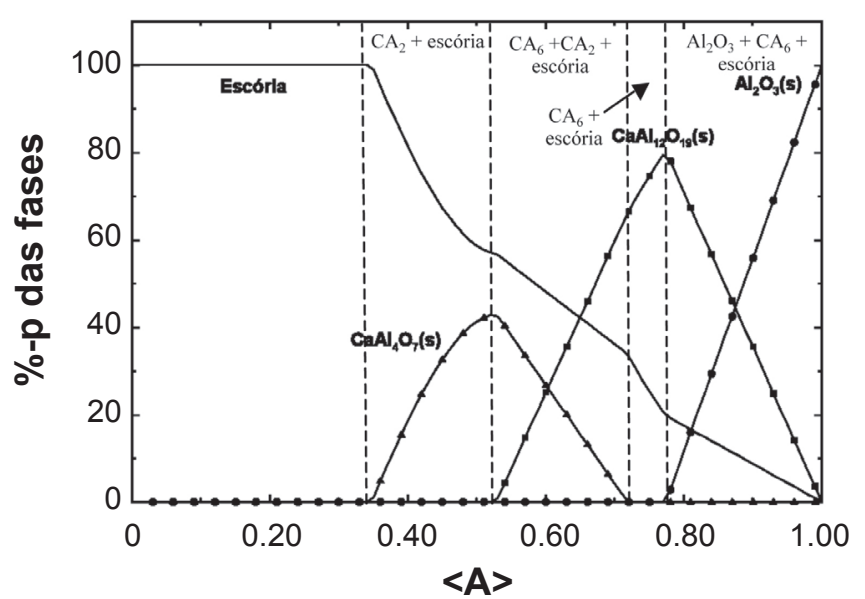

Figura 8: Interação entre escória e agregados de alumina porcentagem em peso das fases formadas em função do avanço da reação $<\mathrm{A}>$ a $1600{ }^{\circ} \mathrm{C}$.

[Figure 8: Slag and alumina aggregates interaction - phases generated, weight percentage as a function of the reaction rate $<A>$ at $1600^{\circ} \mathrm{C}$.]

$<0,72$. $\mathrm{CA}_{2}$ será a última fase sólida formada em contato com a escória líquida $(0,34<\mathrm{A}<0,52)$. Estes dados coletados nas simulações são confirmados na prática, conforme mostrado na Fig. 9. Por meio destas análises foi possível verificar que os cálculos termodinâmicos estão de acordo com as transformações microestruturais dos materiais em questão. As informações fornecidas pelo programa FactSage podem assim auxiliar no entendimento da seqüência das etapas de reação e também na previsão das fases que serão formadas a partir da interação entre líquidos e sólidos. 


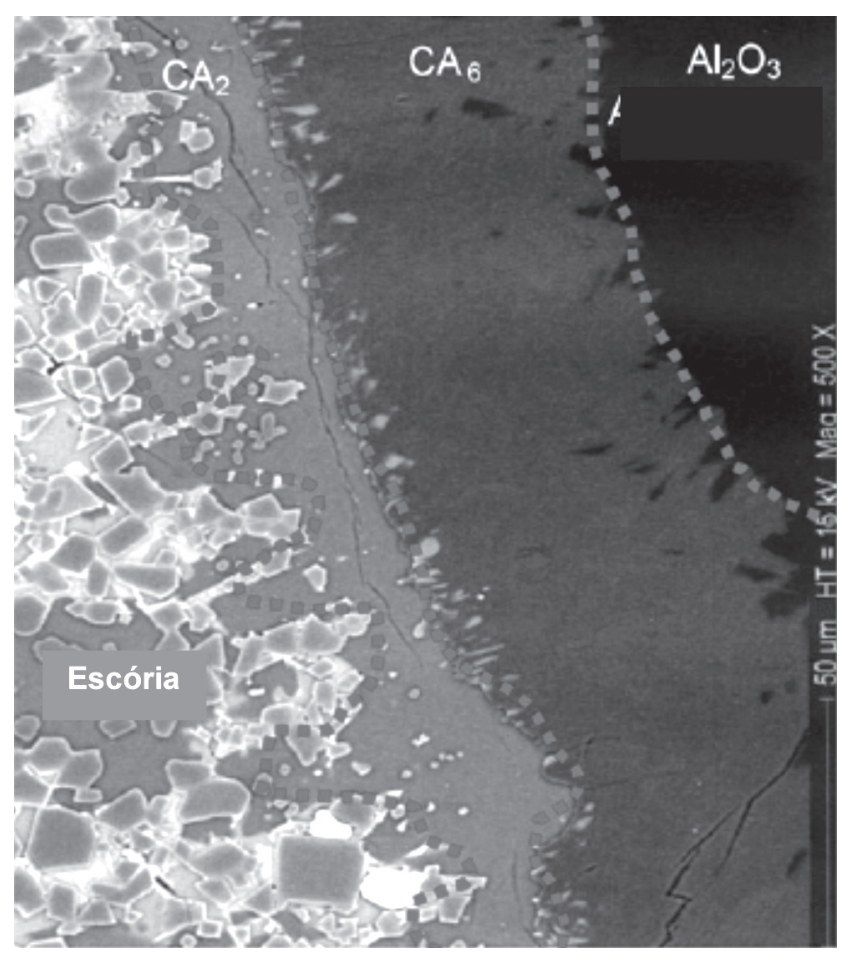

Figura 9: Micrografia obtida por MEV da interface do agregado de $\mathrm{Al}_{2} \mathrm{O}_{3}$ após reagir com a escória líquida [1].

[Figure 9: SEM image of the $\mathrm{Al}_{2} \mathrm{O}_{3}$ aggregates after the reaction with liquid slag [1].]

Efeito da adição de antioxidantes no comportamento de corrosão e oxidação dos refratários contendo carbono

Cálculos termodinâmicos não são usados somente para prever o comportamento de reação entre escórias e refratários, mas também para avaliar a atuação de antioxidantes a elevadas temperaturas em materiais que contenham carbono em sua composição. Alguns trabalhos [15-17, 20] utilizam ferramentas para análise termodinâmica e microestrutural com o objetivo de avaliar o efeito da adição de diferentes antioxidantes na resistência a corrosão de refratários contendo carbono. Os antioxidantes mais estudados são $\mathrm{Al}, \mathrm{Si}, \mathrm{Si}_{3} \mathrm{~N}_{4}$, $\mathrm{BN}, \mathrm{B}_{2} \mathrm{O}_{3}$ e $\mathrm{B}_{4} \mathrm{C}$. A maioria dos trabalhos publicados baseia-se na avaliação da corrosão por meio de testes estáticos, como por exemplo, cup test. Acredita-se que este tipo de ensaio seja o mais adequado para comparação com os resultados das simulações, pois neste caso não há gradientes de temperatura e movimentação da escória e, consequientemente, as reações tendem a avançar até que seja atingida a condição de equilíbrio. As amostras obtidas nos ensaios estáticos também permitem a visualização e avaliação da escória (após resfriamento), da zona de corrosão e do refratário que não sofreu reação [15, 16]. Os cálculos termodinâmicos permitem ainda prever os constituintes da escória, refratário e fases formadas na zona de corrosão, de acordo com as condições usadas nos testes práticos. Alguns autores [15] confirmaram que as várias simulações termodinâmicas realizadas em seu estudo ajudaram a complementar os resultados experimentais e melhor entender
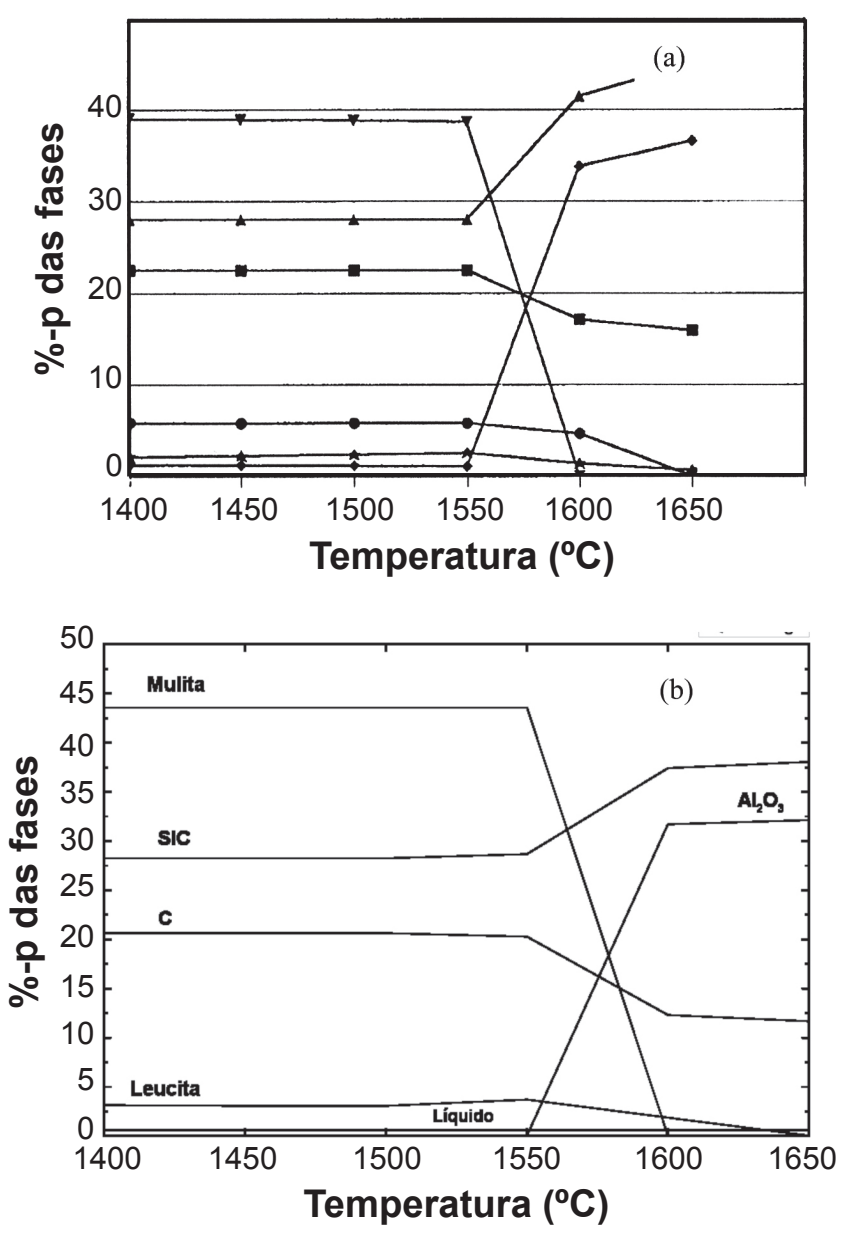

Figura 10: Reprodução da evolução das fases do refratário $\mathrm{Al}_{2} \mathrm{O}_{3}$ $\mathrm{SiO}_{2}$-SiC-C sem antioxidantes quando aquecido em diferentes temperaturas e em atmosfera redutora. Em (a) : ( $\square)$ carbono, $(\downarrow)$

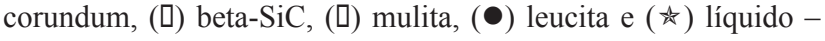
resultado experimental [15] e (b) dados gerados no FactSage.

[Figure 10: Reproduction of the $\mathrm{Al}_{2} \mathrm{O}_{3}-\mathrm{SiO}_{2}-\mathrm{SiC}-\mathrm{C}$ refractory phases evolution (without antioxidant) when treated at different temperatures and under reducing atmosphere. In (a): (অ) carbon,

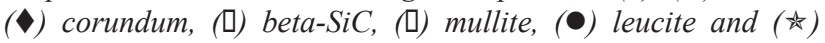
liquid - from experimental results [15] and (b) values generated by FactSage.]

os mecanismos de atuação dos antioxidantes (Al, $\mathrm{Si}, \mathrm{Si}_{3} \mathrm{~N}_{4}$, $\mathrm{BN}, \mathrm{B}_{2} \mathrm{O}_{3}, \mathrm{~B}_{4} \mathrm{C}$ ) em concretos do sistema $\mathrm{Al}_{2} \mathrm{O}_{3}-\mathrm{SiO}_{2}-$ SiC-C. A partir dos dados coletados experimentalmente foi concluído que a adição de $\mathrm{Si}$ e $\mathrm{Si}_{3} \mathrm{~N}_{4}$ ajudou a diminuir a resistência a penetração dos líquidos na microestrutura dos refratários avaliados, devido a oxidação indireta sofrida pelo $\mathrm{C}$, levando a formação de $\mathrm{SiC}$. $\mathrm{B}_{4} \mathrm{C}$ e $\mathrm{B}_{2} \mathrm{O}_{3}$ também afetaram negativamente a resistência a corrosão em virtude da formação de fases líquidas contendo boro. Por outro lado, Al e BN não influenciaram diretamente a corrosão dos concretos em estudo. As previsões termodinâmicas realizadas no programa $\mathrm{F}^{*} \mathrm{~A} * \mathrm{C} * \mathrm{~T}$ e apresentadas por Chan et al. [15] foram reproduzidas aqui usando o FactSage. Resultados muito semelhantes foram obtidos (conforme apresentado na Fig. 10), porém como não são fornecidos todos os detalhes das composições do refratário, foram constatadas 


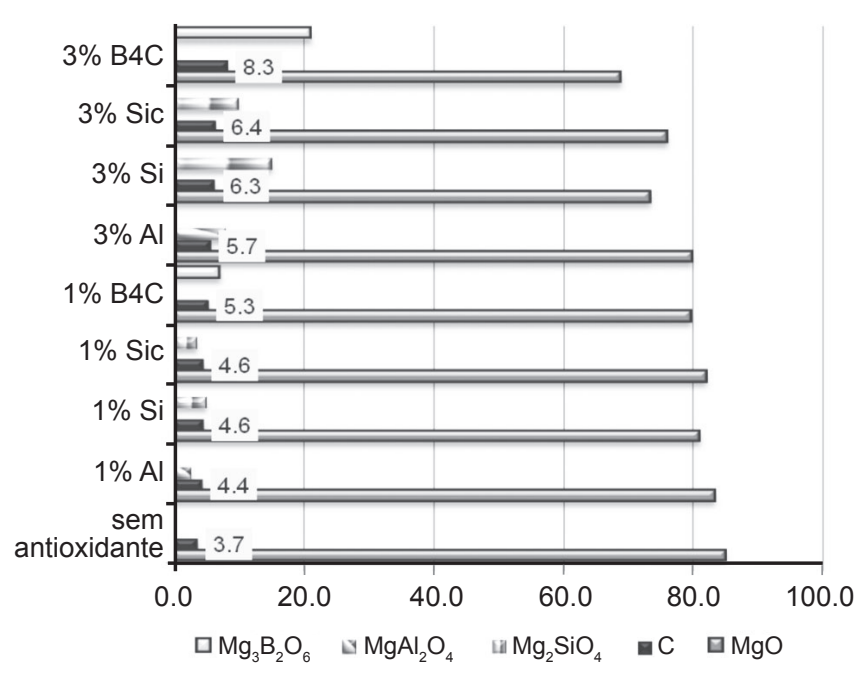

Figura 11: Fases formadas na queima de refratários de $\mathrm{MgO}-\mathrm{C}$, a $1500{ }^{\circ} \mathrm{C}$, em atmosfera oxidante. (dados simulados neste trabalho no FactSage, tomando como base os valores fornecidos no artigo de Gokce et al.[16]).

[Figure 11: Phases generated with the thermal treatment of the $\mathrm{MgO}-\mathrm{C}$ refractory at $1500^{\circ} \mathrm{C}$ under oxidizing atmosphere. (results attained in this work by the FactSage using the experimental results provided by Gokce et al.[16]).]

pequenas diferenças nas quantidades das fases formadas. Outros trabalhos abordam ainda a atuação dos antioxidantes na prevenção ou inibição da oxidação do carbono [16, 20]. Por exemplo, Gokce et al. [16] estudou o comportamento dos antioxidantes $\mathrm{Al}, \mathrm{Si}, \mathrm{SiC}$ e $\mathrm{B}_{4} \mathrm{C}$ a 1300 e $1500{ }^{\circ} \mathrm{C}$, quando adicionados a refratários de $\mathrm{MgO}-\mathrm{C}$. De acordo com os resultados experimentais, a adição de 1 e $3 \%$-p de $\mathrm{B}_{4} \mathrm{C}$ e $\mathrm{Si}$ contribui fortemente para a diminuição da perda de carbono dos refratários nas temperaturas avaliadas. Com o objetivo de verificar a validade das simulações termodinâmicas para este tipo de avaliação, a partir dos dados reportados no artigo citado foram realizadas algumas análises complementares com o programa FactSage. A Fig. 11 exibe a porcentagem em peso das fases formadas na temperatura de $1500{ }^{\circ} \mathrm{C}$, em atmosfera oxidante, quando a condição de equilíbrio é atingida. As fases sugeridas nas simulações estão de acordo com os dados das análises de difração de raios X e microscopia eletrônica de varredura apresentados no trabalho [16]. As microestruturas das amostras que continham $\mathrm{Al}$ e $\mathrm{B}_{4} \mathrm{C}$ como antioxidantes, comprovam a formação das fases $\mathrm{MgAl}_{2} \mathrm{O}_{4}$ e $\mathrm{Mg}_{3} \mathrm{~B}_{2} \mathrm{O}_{6}$ nos materiais avaliados. Além disso, de acordo com os resultados experimentais, o $\mathrm{B}_{4} \mathrm{C}$ foi o antioxidante mais efetivo e que proporcionou maior resistência a oxidação do carbono do refratário do sistema $\mathrm{MgO}-\mathrm{C}$. Este resultado concorda com os dados fornecidos pela análise termodinâmica, pois conforme mostrado na Fig. 9, quando 3\%-p de $\mathrm{B}_{4} \mathrm{C}$ é adicionado ao refratário, o teor de carbono residual presente no material é superior.

\section{Oxidação do $\mathrm{SiC}$}

$\mathrm{O}$ efeito da adição de espinélio em concretos $\mathrm{Al}_{2} \mathrm{O}_{3}$ SiC-C e seu papel na oxidação do carbeto de silício também tem sido alvo de algumas investigações [28-31]. Estes autores demonstraram a partir de ensaios experimentais que a presença de espinélio pode ter acelerado a oxidação do $\mathrm{SiC}$ devido principalmente: a formação de $\mathrm{Mg}(\mathrm{g})$ e $\mathrm{MgO}(\mathrm{g})$ a partir das partículas de espinélio, e posterior reação do espinélio com $\mathrm{SiO}(\mathrm{g})$, que é gerado pela oxidação do $\mathrm{SiC}$. Acredita-se também que o $\mathrm{MgO}(\mathrm{g})$ pode combinar com o filme de $\mathrm{SiO}_{2}$ formado ao redor das partículas de $\mathrm{SiC}$ e acelerar a sua oxidação $[28,30]$. Apesar de ter sido demonstrado experimentalmente que a fase espinélio pode afetar a oxidação do $\operatorname{SiC}[29,31]$, esta tendência não foi observada nos cálculos termodinâmicos. A Tabela II apresenta os resultados das simulações para várias composições contendo diferentes teores de $\mathrm{MgAl}_{2} \mathrm{O}_{4}$, na temperatura de $1550{ }^{\circ} \mathrm{C}$ e em atmosfera oxidante. $\mathrm{O}$ fato do teor resultante de $\mathrm{SiC}$ ser o mesmo para todas as composições pode ser justificado devido aos resultados representarem uma condição de equilíbrio termodinâmico. Talvez, a variação da oxidação do $\mathrm{SiC}$ dependa fortemente da cinética da reação, sendo que nos ensaios experimentais realizados [29, 31] não foi alcançada a condição de equilíbrio do sistema estudado. Novas investigações e análises ainda são necessárias para melhor entender o papel do espinélio na oxidação do SiC. Alguns autores ainda estudaram a oxidação

Tabela II - Resultados das simulações envolvendo $\mathrm{MgAl}_{2} \mathrm{O}_{4}$ e $\mathrm{SiC}$.

[Table II - Simulated results involving $\mathrm{MgAl}_{2} \mathrm{O}_{4}$ and $\mathrm{SiC}$ ].

\begin{tabular}{|c|c|c|c|c|c|c|c|c|c|}
\hline \multicolumn{5}{|c|}{ Dados preliminares [28] } & \multicolumn{5}{|c|}{$\begin{array}{l}\text { Resultados das simulações realizadas no presente } \\
\text { trabalho }\end{array}$} \\
\hline Composição & $\mathrm{Al}_{2} \mathrm{O}_{3}$ & $\mathrm{MgO}$ & $\mathrm{SiC}$ & $\mathrm{CaO}$ & Líquido & $\mathrm{MgAl}_{2} \mathrm{O}_{4}$ & $\mathrm{Al}_{2} \mathrm{O}_{3}$ & $\mathrm{SiC}$ & $\mathrm{C}$ \\
\hline $\mathrm{I}$ & 30 & - & 70 & 1 & 5,9 & - & 24,1 & 67,5 & 0,7 \\
\hline II & 27,02 & 2,89 & 70 & 1 & 11,3 & 4,5 & 18,9 & 67,5 & 0,7 \\
\hline III & 24,04 & 5,78 & 70 & 1 & 11,3 & 14,7 & 8,6 & 67,5 & 0,7 \\
\hline IV & 21,6 & 8,67 & 70 & 1 & 10,3 & 24,2 & - & 67,5 & 0,7 \\
\hline V & 24,18 & 5,64 & 70 & 1 & 11,3 & 14,2 & 9,1 & 67,5 & 0,7 \\
\hline VI & 26,7 & 3,15 & 70 & 1 & 11,3 & 5,4 & 17,9 & 67,5 & 0,7 \\
\hline VII & 21,72 & 7,74 & 70 & 1 & 11,3 & 21,6 & 1,3 & 67,5 & 0,7 \\
\hline
\end{tabular}


Tabela III - Avaliação termodinâmica da oxidação do SiC na temperatura de $1200{ }^{\circ} \mathrm{C}$ e $10 \mathrm{~atm}$.

[Table III - Thermodynamic evaluation of the SiC oxidation at $1200^{\circ} \mathrm{C}$ and $10 \mathrm{~atm}$.

\begin{tabular}{lccc}
\hline Composição & $\mathrm{SiC}(\%-p)$ & $\mathrm{C} \mathrm{( \% -p)}$ & $\mathrm{SiO}_{2}(\%-p)$ \\
\hline $\mathrm{SiC}+\mathrm{ar}$ & 62,45 & 33,41 & 6,68 \\
$\mathrm{SiC}+\mathrm{ar}+15 \% \mathrm{H}_{2} \mathrm{O}$ & 56,74 & 7,17 & 36,12 \\
\hline
\end{tabular}

do $\mathrm{SiC}$ a $1200{ }^{\circ} \mathrm{C}$ com tratamentos térmicos abrangendo tempos de 100 a $2000 \mathrm{~h}$, em presença de ar e ar $+15 \% \mathrm{H}_{2} \mathrm{O}$ a pressões de até $10 \mathrm{~atm}$ [32]. De acordo com este trabalho citado, a presença de vapor de água e alta pressão (10 atm) acelerou drasticamente a oxidação do $\mathrm{SiC}$ e uma camada porosa e outra mais densa de $\mathrm{SiO}_{2}$ foram encontradas na superfície do material avaliado. A espessura da camada porosa de $\mathrm{SiO}_{2}$ também aumentará quando o $\mathrm{SiC}$ for exposto a alta temperatura com a presença de vapor de água no ar. Nos cálculos termodinâmicos aqui elaborados também foi obtido uma maior quantidade de $\mathrm{SiO}_{2}$ quando vapor de água foi considerado (veja resultados na Tabela III). Tortorelli et al. [32] não citam em valores numéricos qual a extensão da oxidação do $\mathrm{SiC}$, mas comparando as micrografias exibidas no trabalho citado com os resultados fornecidos pelo FactSage, acredita-se que os dados são coerentes com o observado na prática.

\section{ANÁLISE COMPLEMENTAR}

Outra forma de análise da interação entre líquidos e refratários envolve a simulação da penetração da escória líquida no interior do sólido. Neste caso, inicialmente é posto em contato a escória e o refratário na proporção de $50 \%$ cada um. Após a reação inicial entre os materiais e conseqüente modificação da composição da escória, este novo líquido (agora enriquecido com as fases do sólido que se dissolveram) é colocado em contato com a composição original do refratário e um novo cálculo é realizado. A cada nova reação, este mesmo procedimento é realizado: a composição atual do líquido é colocada em contato com os dados do refratário inicial. A vantagem deste tipo de análise é que ela permite visualizar de forma mais clara as possíveis fases formadas no contato da escória com o refratário, representando melhor o que ocorre na prática. Além disso, as mudanças da composição do líquido influenciarão o avanço da reação e a precipitação das fases na interface entre

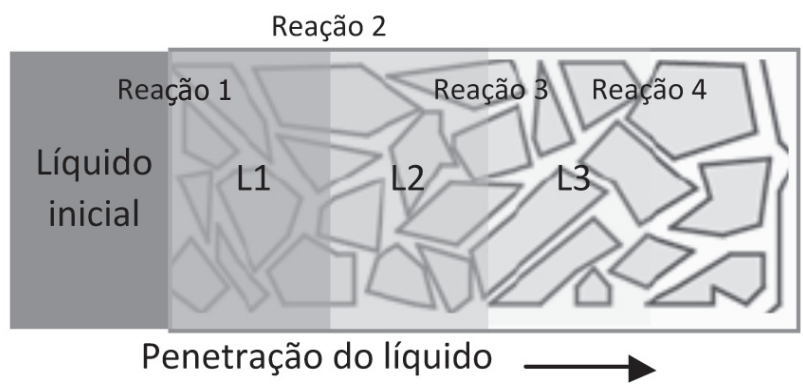

Figura 12: Esquema que ilustra as mudanças da composição do líquido penetrando o material refratário.

[Figure 12: Sketch of the liquid composition changes after reaction with the refractory material.]

sólido-líquido. A Fig. 12 apresenta um esquema indicando o princípio de tal análise. Como por exemplo, uma nova simulação foi realizada utilizando o método citado acima. Os materiais avaliados foram: sólido - agregados de $\mathrm{Al}_{2} \mathrm{O}_{3}$ e líquido - escória sintética contendo $13 \% \mathrm{Al}_{2} \mathrm{O}_{3}-40 \%$ $\mathrm{CaO}-32 \% \mathrm{SiO}_{2}-15 \% \mathrm{MgO}(\%-\mathrm{p})$. Comparando os dados apresentados na Tabela IV com a micrografia mostrada na Fig. 9, nota-se que os resultados encontrados estão de acordo com os ensaios experimentais - quanto as fases que foram formadas na interface entre sólido e líquido e as suas devidas proporções. Vale ressaltar que dos artigos pesquisados, nenhum deles apresentou este tipo de cálculo. Porém, acredita-se que as mudanças na composição da fase líquida irão influenciar as possíveis reações e a quantidade das fases que poderão se formar na interface entre os materiais. Isto faz com que, este tipo de cálculo nos leve a obtenção de resultados mais precisos.

\section{CONCLUSÕES}

Após as análises dos diversos materiais e diferentes situações mostradas nas seções anteriores, foi possível comprovar as vantagens e facilidades que uma ferramenta termodinâmica pode proporcionar para o melhor entendimento das transformações sofridas na microestrutura dos materiais. O processo de corrosão é o mais estudado por meio de simulações, pois este se trata de um fenômeno complexo e que ainda não é claramente entendido. No entanto, diversos processos, aplicações e materiais podem ser estudados com o uso de programas de cálculos termodinâmicos. Neste trabalho os exemplos apresentados envolveram: corrosão de refratários quando em contato com

Tabela IV - Resultados das simulações envolvendo a penetração da escória no $\mathrm{Al}_{2} \mathrm{O}_{3}$ sólido.

[Table IV - Simulated results involving slag penetration into solid $\mathrm{Al}_{2} \mathrm{O}_{3}$ ].

\begin{tabular}{|c|c|c|c|}
\hline Início & Reação 1 & Reação 2 & Reação 3 \\
\hline $50 \%-\mathrm{p} \mathrm{Al}_{2} \mathrm{O}_{3}(\mathrm{R})$ & 66,15\%-p Líquido 1 & 47,95\%-p Líquido 2 & 52,69\%-p Líquido 3 \\
\hline 50\%-p Escória (L) & $\begin{array}{l}\text { 22,45\%-p } \mathrm{MgAl}_{2} \mathrm{O}_{4} \\
11,35 \%-\mathrm{CA}_{2}\end{array}$ & $\begin{array}{l}\text { 46,10\%-p CA } \\
5,94 \%-\mathrm{pl}_{2} \mathrm{O}_{3}\end{array}$ & $47,30 \%-\mathrm{p} \mathrm{Al}_{2} \mathrm{O}_{3}$ \\
\hline
\end{tabular}


escórias líquidas, atuação dos antioxidantes na corrosão, oxidação de refratários contendo carbono e oxidação do $\mathrm{SiC}$. A desvantagem destas ferramentas está no fato delas não fornecerem qualquer informação da cinética e distribuição espacial de cada produto de reação formado, e assim, não podem revelar o efeito de cada fase na microestrutura dos refratários em elevadas temperaturas. Além disso, todos os resultados destes cálculos correspondem a uma situação de equilíbrio, condição esta que quase nunca é alcançada nos ensaios práticos. Assim, para o completo entendimento dos mecanismos de reação ambas análises termodinâmica e microestrutural são necessárias. Na maioria dos casos ainda não é possível evitar a realização de testes em laboratórios, os quais podem auxiliar efetivamente na seleção dos materiais. Entretanto, o desempenho dos refratários em ambiente industrial é muito mais complexo e atualmente está longe de ser totalmente entendido.

\section{AGRADECIMENTOS}

À FAPESP pelo apoio recebido e ao Dr. P. Chartrand (Center for Research in Computacional Thermochemistry, Montreal) pelo auxílio na avaliação das simulações termodinâmicas.

\section{REFERÊNCIAS}

[1] J. Berjonneau, P. Pringent, J. Poirier, The development of a thermodynamic model for $\mathrm{Al}_{2} \mathrm{O}_{3}-\mathrm{MgO}$ refractory castable corrosion by secondary metallurgy steel ladle slags, Ceram. Int. 35, 2 (2009) 623-635.

[2] R. A. McCauley, Corrosion of ceramic and composite materials, Marcel Dekker Inc., New York, EUA (2004) 405. [3] W. E. Lee, S. Zhang, Melt corrosion of oxide and oxidecarbon refractories, Int. Mat. Rev. 44 (1999) 77-104.

[4] J. Poirier, M. L. Bouchetou, P. Pringent, J. Berjonneau, An overview of refractory corrosion: observations, mechanisms and thermodynamic modeling, Refract. Applic. Trans. 3, 2 (2007) 2-12.

[5] J. Poirier, Impact of refractory materials on inclusionary cleanliness and steel quality, Ceram. Forum Int. 85, 10 (2008) E59-E69.

[6] J. Poirier, M. L. Bouchetou, Influence of iron oxides on corrosion of refractories used in steel making, Refractories Applic. Trans. 2, 3 (2006) 2-8.

[7] W. S. Resende, R. M. Stoll, S. M. Justus, R. M. Andrade, E. Longo, J. B. Baldo, E. R. Leite, C. A. Paskocimas, L. E. B. Soledade, J. E. Gomes, J. A. Varela, Key features of alumina/ magnesia/graphite refractories for steel ladle lining, J. Eur. Ceram. Soc. 20 (2000) 1419-1427.

[8] S. M. Justus, S. N. Silva, F. Vernilli Jr., A. Mazine, R. G. Toledo, R. M. Andrade, O. R. Marques, E. Longo, J. B. Baldo, J. A. Varela, Post mortem study of $\mathrm{Al}_{2} \mathrm{O}_{3} / \mathrm{SiC} / \mathrm{Cl}$ $\mathrm{MgAl}_{2} \mathrm{O}_{4}$ ceramic lining used in torpedo cars, Ceram. Int. 31 (2005) 897-904.

[9] J. Poirier, F. Qafssaoui, J. P. Ildefonse, M. L. Bouchetou, Analysis and interpretation of refractory microstructures in studies of corrosion mechanisms by liquid oxides, J. Eur. Ceram. Soc. 28, 8 (2008) 1557-1568.

[10] S. Zhang, W. E. Lee, Use of phase diagrams in studies of refractories corrosion, Int. Mater. Rev. 45, 2 (2000) 4158.

[11] V. A. Rovnushkin, É. A. Visloguzova, S. A. Spirin, E. V. Shekhovtsov, V. V. Kromn, A. A. Metelkin, Composition of ladle slag and refractory materials and its effect on the wear resistance of the lining of an $\mathrm{RH}$ vacuum degasser, Refract. Ind. Ceram. 46, 3 (2005) 33-36.

[12] É. A. Visloguzova, A. A. Metelkin, L. V. Zorikhina, I. G. Maryasev, D. A. Tereshchenko, L. M. Mikhailovskaya, The effect of degassing technology parameters and the quality of periclase-chromite refractories on ther wear resistance in vacuum chamber lining, Refract. Ind. Ceram. 47, 5 (2006) 35-38.

[13] C. J. Treadgold, Behaviour of inclusions in RH vacuum degasser, Ironmaking Steelmaking 30, 2 (2003) 120-124.

[14] E. M. M. Ewais, Carbon based refractories, J. Ceram. Soc. Japan 112, 10 (2004) 517-532.

[15] C. F. Chan, B. B. Argent, W. E. Lee, Influence of additives on slag resistance of $\mathrm{Al}_{2} \mathrm{O}_{3}-\mathrm{SiO}_{2}-\mathrm{SiC}$-C refractory bond phases under reducing atmosphere, J. Am. Ceram. Soc. 81, 12 (1998) 3177-3188.

[16] A. S. Gokce, C. Gurcan, S. Ozgen, S. Aydin, The effect of antioxidants on the oxidation behavior of magnesiacarbon refractory bricks, Ceram. Int. 34 (2008) 323-330.

[17] S. Zhang, W. E. Lee, Influence of additives on corrosion resistance and corroded microstructures of $\mathrm{MgO}-\mathrm{C}$ refractories, J. Eur. Ceram. Soc. 21 (2001) 2393-2405.

[18] M. Rigaud, New additives in carbon-bondedrefractories, Ceramic: charting the future, Techna Srl. (1995) 399.

[19] A. P. Luz, V. C. Pandolfelli, Atuação dos antioxidantes em refratários contendo carbono, Cerâmica 53, 328 (2007) 334-344.

[20] S. Zhang, N. J. Marriott, W. E. Lee, Thermochemistry and microstructures of $\mathrm{MgO}-\mathrm{C}$ refractories containing various antioxidants, J. Eur. Ceram. Soc. 21 (2001) $1037-$ 1047.

[21] H. Li, N. Yoshihiko, Z. Dong, M. Zhang, Application of the FactSage to predict the ash melting behavior in reducing conditions, Chinese J. Chem. Eng. 14, 6 (2006) 784-789.

[22] J. C. van Dyk, F. B. Waanders, S. A. Benson, M. L. Laumb, K. Hack, Viscosity predictions of the slag composition of gasified coal, utilizing FactSage equilibrium modeling, Fuel 88 (2009) 67-74.

[23] C. W. Bale, P. Chartrand, S. A. Degterov, G. Eriksson, K. Hack, R. Ben Mahfoud, J. Melançon, A. D. Peltron, S. Petersen, FactSage thermochemical software and databases, Calphad 26, 2 (2002) 189-228.

[24] G. Eriksson, A. D. Pelton, Critical evaluation and optimization of the thermodynamic properties and phase diagrams of the $\mathrm{CaO}-\mathrm{Al}_{2} \mathrm{O}_{3}, \mathrm{Al}_{2} \mathrm{O}_{3}-\mathrm{SiO}_{2}$ and $\mathrm{CaO}-\mathrm{Al}_{2} \mathrm{O}_{3}-$ $\mathrm{SiO}_{2}$ systems, Metall. Mater. Trans. B. 24, 5 (1993) 807-816. [25] P. Wu, G. Eriksson, A. D. Pelton, Critical evaluation and optimization of the thermodynamic properties and phase diagrams of the CaO-FeO, CaO-MgO, CaO-MnO, FeO- 
$\mathrm{MgO}, \mathrm{FeO}-\mathrm{MnO}$ and $\mathrm{MgO}-\mathrm{MnO}$ systems, J. Am. Ceram. Soc. 76 (1993) 2065-2075.

[26] M. E. F. Osborn, R. C. de Vries, K. H. Gee, H. M. Kraner, Slag Atlas Verlag Stahleisen GmbH, Düsseldorf, Alemanha (1995) 156-157.

[27] H. Sarpoolaky, S. Zhang, B. B. Argent, W. E. Lee, Influence of grain phase on slag corrosion of low-cement castable refractories, J. Am. Ceram. Soc. 84, 2 (2001) 426434.

[28] Y. Hamazaki, T. Kaneshige, H. Sumimura, M. Namba, The effect of spinel addition on $\mathrm{Al}_{2} \mathrm{O}_{3}-\mathrm{SiC}-\mathrm{C}$ castables, Shinagawa Tech. Rep. 41 (1998) 15-24.

[29] T. Kageyama, Y. Nogami, M. Kitamura, T. Iida, The deterioration and damage of trough castables containing alumina-magnesia spinel due to long-term use, Shinagawa Tech. Rep. 50 (2007) 31-40.

[30] M. Iida, Y. Toritani, S. Tanaka, Effect of spinel and silicon-carbide on the corrosion resistance of the castable for blast furnace trough, Proc. Unified Int. Tech. Conf. Refractories, Kyoto, Japão (1995) 151-158.

[31] M. Iida, N. Muroi, Effect of spinel on oxidization of silicon carbide and corrosion resistance to metal line castable for blast furnace trough, Kawasaki Rozai Tech. Rep. 32 (2001) 2-10.

[32] P. F. Tortorelli, K. L. More, Effects of high water-vapor pressure on oxidation of silicon carbide at $1200^{\circ} \mathrm{C}$, J. Am. Ceram. Soc. 86, 8 (2003) 1249-1255.

(Rec. 06/07/2009, Ac. 25/09/2009) 